\title{
A REVIEW OF EDUCATIONAL RECOMMENDER SYSTEMS FOR TEACHERS
}

\author{
Mbarek Dhahri ${ }^{1}$ and Mohamed Koutheair Khribi ${ }^{2}$ \\ ${ }^{1}$ Higher School of Sciences and Technologies of Tunis, University of Tunis, Tunisia \\ ${ }^{2}$ Technologies of Information and Communication Lab \\ Higher School of Sciences and Techniques of Tunis, University of Tunis, Tunisia \\ 5, Av. Taha Hussein, B.P. 56, Bab Mnara 1008, Tunis, Tunisia
}

\begin{abstract}
Recommender Systems (RS) in e-learning has attracted several researchers aiming basically at scaffolding learners in locating relevant learning resources that meet their learning needs and profiles. Whereas a number of review studies have been carried out in the area of educational recommender systems, there is a limited information in the literature review in the specific domain of recommendation systems for teachers. The objective of this work is to summarize the current research efforts in the field of teacher-oriented recommender systems. By performing this systematic review, 32 papers were selected for further analysis. The obtained results show that educational portals and repositories are widely used as learning environments where recommendations occur. The finding of this review further show that personalized recommendations for teachers and teaching practices improvements are the main issues addressed by RS for teachers. Furthermore, the hybrid approach for recommendation and the evaluation by experiment are the most used, occurring in $43,75 \%$ of the selected reviewed papers. We are availing the key findings of this work to propose a teacher recommender system that provides teachers with the most relevant open educational resources (OER) retrieved from collections of resources aligned to the UNESCO ICT Competency Framework for Teachers (CFT).
\end{abstract}

\section{KEYWORDS}

e-Learning, Recommender System, Personalization, Teacher Recommendation, ICT Competencies for Teachers, Online Learning Environments

\section{INTRODUCTION}

Recommender systems (RSs) can be defined as software tools which provide suggestions for the most relevant items to particular users ( $\mathrm{Lu}$ et al., 2015). They have been implemented in a wide range of application areas including e-commerce, e-library and e-learning. Commonly used recommendation techniques include Content-based filtering $(\mathrm{CBF})$, Collaborative filtering $(\mathrm{CF})$, knowledge-based $(\mathrm{KB})$ and hybrid approaches (Verbert et al., 2012).

In the context of Technology Enhanced Learning (TEL), recommender system has become more and more popular during the last decade, especially with the widespread of online learning environments and repositories (Lu et al., 2015). Educational recommender systems aim basically (1) to help learners/teachers to find different types of learning materials through the learning/teaching process based on their individual interests; (2) to recommend learning pathways or educational scenarios; (3) to suggest users with same profiles (i.e., peers); (4) to predict appropriate rates and ranks, etc. (Khribi et al., 2015). The majority of existing TEL RS targets learners and attempts to integrate their personal attributes in the recommendation process (Sergis et al., 2014a). On the other hand, as there is an increased interest by teachers to improve their information and communication technology (ICT) in education competencies and their learning and teaching practices availing learning technologies, some existing researches have been conducted attempting to recommend adequate training content and educational resources for teachers based on their profiles and needs.

In this paper, we present a systematic review of existing recommender systems for teachers during the period 2009 to 2021 . The objective of this review is threefold: (1) identify learning environments where recommendation to teachers occur, (2) investigate addressed issues, and (3) determine which recommendation approaches and related evaluation methods were used. 
The rest of the paper is organized as follows: Section 2 details the research method, Section 3 provides proposed answers to key research questions as well as discusses the main raised issues. Finally, Section 4 presents the conclusion and future work.

\section{METHODOLOGY}

The proposed review has been carried out based on the methodological provided by (Kitchenham and Charters, 2007), (Rivera et al., 2018) and (Pinho et al., 2019). This method highlights several steps that guide the systematic reviews: identification of research questions, formulation of the research strategy, selection of primary studies according to inclusion/exclusion criteria, and the mapping study findings. These steps are further featured in the remainder of this section.

\subsection{Research Questions}

The research questions addressed by this study are:

1. What are the major types of online learning environments in which recommendation systems are included? This research question aims to spot the most prominent types of online learning environments in which recommendations occur, to name but a few: Learning Management System (LMS), Courseware, Repositories, Learning Activity Management System (LAMS), etc. Findings related to this question would help a lot to identify the most common online learning environments in which the teacher-oriented recommender systems are integrated, and those which are so far overlooked.

2. What are the main issues addressed by teacher recommendation systems? In this research question, issues refer to the challenges addressed by the teacher RS, e.g., personalized recommendations for teachers, improving teaching by recommending suitable practices, etc. Results of this question would help understanding RS added values and strengths when integrating a teacher-oriented RS in such learning environment.

3. What recommendation approaches are mostly used in teacher recommendation systems? This research question aims to investigate major approaches used to generate recommendations such as Content-Based Filtering (CBF), Collaborative Filtering (CF), etc. which would be understanding commonly used approaches and techniques applied in teacher-oriented recommendation systems.

4. What evaluation methods are applied to prove the efficiency of teacher recommendation systems? This research question aims to indicate which validation strategies are applied to recommendation systems e.g. survey, experiment, etc. This would help shedding light on how existing teacher-oriented recommendations are evaluated.

\subsection{Search Process}

Searching and locating suitable resources for the study were established through online search from the following digital sources: IEEE Xplore, ScienceDirect, SpringerLink, Taylor \& Francis and Google Scholar. We set our database search query using the following terms with the combination operator "AND" and "OR" as: Education AND (Teacher OR Educator) AND "Recommender System". The number of studies found was 602 eventually relevant papers. We read the papers' titles, abstracts, and keywords. This filtering procedure produced a total of 32 papers (note that the same paper may occurs in more than one source). The selected primary studies were then read and analyzed. The research was undertaken in April 2020 and updated in January 2021.

\subsection{Selection of Criteria}

In this step, in order for the selection of existing studies to be ensured seamlessly, we defined exclusion criteria to decide whether a paper is directly linked to search query:

- Papers not written in English. 
- Papers not targeting teacher-oriented RS.

- Duplicates studies: only the most current included.

- Summary articles, tutorials, workshop reports.

If the study met at least one of the criteria listed below, it would be excluded from the process. The table 1 shows the number of studies retrieved and relevant after the application of the exclusion criteria.

Table 1. Summary table of search results

\begin{tabular}{lll}
\hline Source & Number of studies & Selected \\
\hline Springer & 254 & 11 \\
IEEE Xplore & 70 & 9 \\
ScienceDirect & 180 & 5 \\
Google Scholar & First 30 results & 5 \\
Taylor \& Francis & 68 & 2 \\
Total & $\mathbf{6 0 2}$ & $\mathbf{3 2}$ \\
\hline
\end{tabular}

\section{REVIEW OF EXISTING RS FOR TEACHERS}

In this section, we present an overview of selected articles and results of our survey on teacher-oriented recommender systems.

\subsection{Overview}

Authors in (García et al., 2009) affirmed that educational RSs can help teachers to improve learning performance. Authors in (Manouselis et al., 2010) concluded in their study that as opposed to movie or music recommender, the field of learning resources is very diverse and complex due to the variety in the potential educational uses of learning resource. In (Garcia-Valdez et al., 2010), the authors explored the use of fuzzy approach in educational recommender systems. (Brusilovsky et al., 2010) demonstrated how social navigation can be implemented in the context of a large distributed educational digital library. (Zapata et al., 2011) proposed a hybrid recommendation method to assist teachers in the search and selection process in learning objects repositories. (Bahritidinov et al., 2011) proposed a recommendation algorithm that recommends relevant collaborative teams of teachers to the coordinators of courses or units of learning. In (Ferreira-Satler et al., 2012), the authors demonstrated how a fuzzy ontology can be used to represent teacher profile into a recommender engine and enhances the teacher's activities into e-learning environment. (Fazeli et al., 2012) proposed a social recommender to assist young teachers to find most suitable peers to address their problems. In other work (Fazeli et al., 2014), the authors enhanced a trust-based recommender algorithm with social data obtained from monitoring the activities of teachers in order to help them to find the most learning resources. Another peer-based recommender system has been proposed by (Miranda et al., 2012) that combines collaborative and content filtering and enriched with contextual information to recommend online comments written by teachers to their peers about their experience related to educational activities in an online educational community. (Limongelli et al., 2013) addressed the problem of helping teachers to retrieve didactic material from a repository through a didactic social network where teachers with similar teaching styles can assist each other to find educational material. In other work (Limongelli et al., 2016), the authors presented a recommender system to assist teachers to build their courses through the Moodle learning management system. (Mottus et al., 2013) identified the goal of generating a visual dashboard for teachers to allow them easy access to complex educational information. (Gallego et al., 2013) proposed a new model to produce proactive context-aware recommendations on resources while creating a new learning object (LO) that a teacher performs by using an authoring tool. (Cobos et al., 2013) proposed a recommendation system of pedagogical patterns allowing teachers to access to patterns that provide solutions to the different problems they meet and assist them to accomplish their goals related to their courses. (Soldatova et al., 2014) addressed the issue of recommending e-learning tools for teaching stuff of engineering disciplines by defining criteria that will be used to create an e-learning recommender system. In 
(Sergis et al., 2014b), (Sergis and Sampson, 2015) and (Sergis and Sampson, 2016), the authors tackled the problem of ignoring the potential benefits of profiling teachers' particular professional characteristics. They proposed a recommender system to help teachers to find LO from existing repositories in a unified manner namely by automatically constructing their ICT complex profiles and exploiting these profiles for more efficient LO selection. (El-Bishouty et al., 2014) developed a smart e-course recommender tool to support teachers to extend their existing e-courses in learning management system by adding a list of recommended LOs to courses. (Zervas et al., 2015) proposed a recommender system to support teachers to find and select the suitable remote and visited labs based on core pedagogical elements of their learning designs and their information and communication technology competences profiles. (Tewari et al., 2015) proposed a recommender system that analyses learner's opinions about contents and recommends the teachers who have uploaded the content of the web site to modify the particular portion of the subject topic which is difficult to understand by learners using opinion mining. In (Revilla Muñoz et al., 2016), the authors defined and implemented a recommender system to support teachers to find the most suitable solutions to their ICT problems from others teachers. (Karga and Satratzemi, 2018) and (Karga and Satratzemi, 2019) found in their research that Mentor, a recommender system integrated into learning activities management system, facilitates the sharing of good practices and help teachers to find a good learning design to rely upon for creating their own.

It is noteworthy that the current review represents the second milestone of an ongoing research aiming at developing a teacher recommender system that is intended to suggest relevant OER aligned to the UNESCO ICT competency framework. The first milestone of the project (Dhahri and Khribi, 2021) explored teachers' ICT competency assessment realm by identifying and analyzing existing tools and approaches for assessing teachers' ICT competency level.

\subsection{Answers to Research Questions}

In this section, we present the results grouped by research questions.

\subsubsection{Learning Environments}

In table 2 we show the results of the first research question found in the selected papers.

Table 2. Distribution by learning environment

\begin{tabular}{lll}
\hline Learning Environment & Number of studies & $\%$ \\
\hline Learning Management System (LMS) & 7 & 21,88 \\
Educational Portal & 10 & 31,25 \\
Repository & 8 & 25,00 \\
Collaborative Authoring Tool & 1 & 3,13 \\
Social Platform & 2 & 6,25 \\
Learning Content Management System (LCMS) & 1 & 3,13 \\
Digital ecosystems & 1 & 3,13 \\
Learning Activity Management System (LAMS) & 2 & 6,25 \\
\hline
\end{tabular}

LMSs are software tools that provide mainly course management functionality and basic facilities of course authoring tools (Soldatova et al., 2014). Educational portal is a web-based interface with learning resources (Manouselis et al., 2010). Repositories are digital libraries for publishing, searching and retrieval of instructional resources (Zapata et al., 2013). Collaborative authoring tools provide environments that facilitate teacher participation in knowledge sharing activities, retrieving, and reusing of materials and activities created by colleagues (Bahritidinov et al., 2011). Social platforms are online social networks designed to support professional development (Fazeli et al., 2012). LCMS provide spaces where teachers publish, catalog and download learning resources (Ferreira-Satler et al., 2012). Digital ecosystems can be considered as platforms for cooperation, sharing and access to knowledge in order to facilitate learning (Mohamed Ali et al., 2017). LAMS are tools for designing, managing and delivering sequences of learning activities (Karga and Satratzemi, 2018). 
Results show that around $31 \%$ of the papers reviewed choose educational portals to make recommendation to teachers due to the user feedbacks (ratings, comments, tagging) that offer a portal. These forms of feedback demonstrated their ability to guide portal users to relevant resources (Brusilovsky et al., 2010). Other primary studies (around 25\%) focused on Learning Objects (LOs) recommendation and personalization into LO repositories. In the educational field, there is a lot of repositories and courseware where teachers can share their resources and locate educational material of interest to reuse (Limongelli et al., 2013). Furthermore, there are around $22 \%$ of the reviewed papers which referred to learning management systems to provide recommendations. As can be seen in Figure 1, few reviewed studies have been focusing on collaborative authoring tools and social platforms. On the other hand, there is a significant interest in using educational portals, then repositories, and learning management systems to provide recommendations for teachers.

\subsubsection{Recommendation Issues}

In table 3 we show the results of the second research question found in the selected papers. Personalized recommendations for teachers and improving teaching practices are the main issues addressed by teacher-oriented RSs (around 34\% for each one). Instead of simple recommendation which provides Top-N items, in a personalized recommendation, the teacher attributes (i.e., prior knowledge, learning style, etc.) are used in the process of recommendation (Sergis and Sampson, 2016). Studies like (Sergis et al., 2014b), (Zervas et al., 2015) and (Sergis and Sampson, 2016) proposed teachers' ICT competence-based LO recommendations. Other studies addressed different issues: social navigation (12.5\%), prediction accuracy, teaching capacity building, support program on ICT for teachers, proactive contextaware recommendations in e-learning.

Table 3. Distribution by issue

\begin{tabular}{lll}
\hline Issue & Number of studies & $\%$ \\
\hline Improve teaching practices & 11 & 34,38 \\
Personalized recommendations for teachers & 11 & 34,38 \\
Social navigation & 4 & 12,50 \\
LO personalized search & 2 & 6,25 \\
Proactive contextaware recommendations in e-Learning & 1 & 3,13 \\
Prediction accuracy & 1 & 3,13 \\
Support program on ICT for teachers & 1 & 3,13 \\
Teachers' capacity building & 1 & 3,13 \\
\hline
\end{tabular}

Figure 2 show the comparative panorama between the results. Therefore, user profiling in teacher-oriented recommender systems should be an important consideration for educational recommendation systems for teachers.

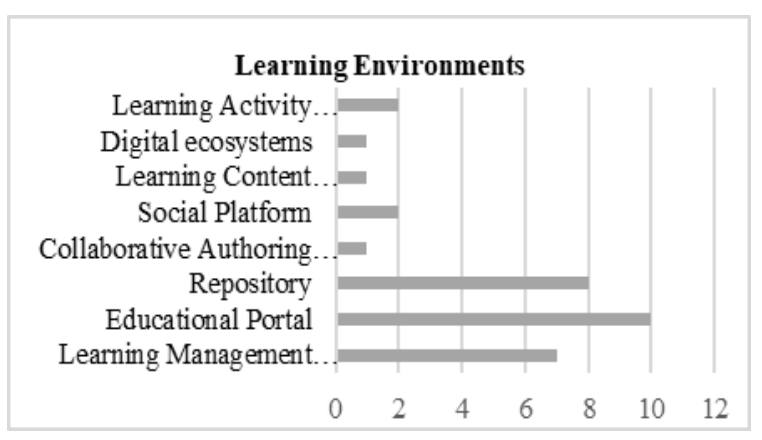

Figure 1. Learning environments

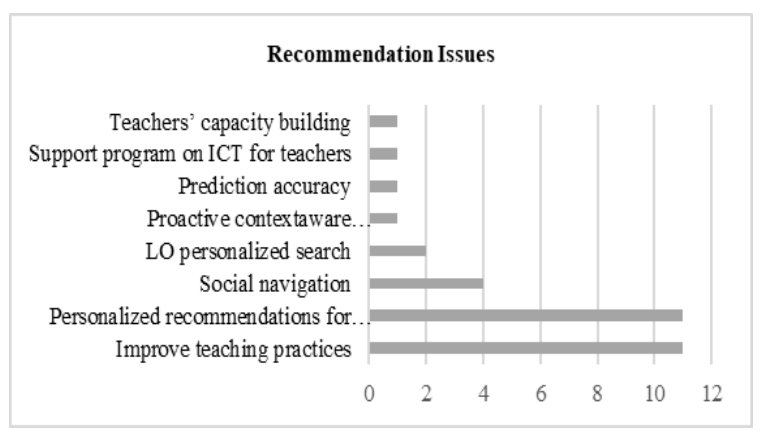

Figure 2. Recommendation issues 


\subsubsection{Recommendation Approaches}

The results discovered in the selected articles related to the third research question are shown in table 4.

Table 4. Distribution by recommendation approach

\begin{tabular}{lll}
\hline Approach & Number of studies & $\%$ \\
\hline Hybrid Filtering & 14 & 43,75 \\
Content-Based Filtering & 9 & 28,13 \\
Collaborative Filtering & 8 & 25,00 \\
Fuzzy-Based & 1 & 3,13 \\
\hline
\end{tabular}

The analysis of the results demonstrates that the hybrid approach is frequently used in teacher-oriented RS. As can be seen in Figure 3, around $44 \%$ of the papers reviewed combine several recommendation techniques. Others recommendation approaches used include collaborative filtering (25\%) and content-based filtering (around 28\%). Collaborative filtering recommendation approaches assist users to make their choices based on the opinions of others users who share same interests (Lu et al., 2015). However, content-based filtering recommendation approaches suggest items that are similar to items already preferred by a specific user (Lu et al., 2015). Other less commonly used approach is fuzzy-based RS. For example, (Ferreira-Satler et al., 2012) utilize fuzzy ontology to represent user profiles into a recommender engine. The most preference of a hybrid approach is to enhance the efficiency of the recommender model and get over the issues of other types of recommender such as collaborative and content-based filtering.

\subsubsection{Evaluation Methods}

The analysis of the results of the fourth research question indicates that around $22 \%$ of the selected studies did not carry out any evaluation method as shown in table 5. Around $44 \%$ of the studies had been evaluated through an experiment. For instance, (Sergis and Sampson, 2016) performed experiments with data from three repositories to demonstrate the benefits of the proposed system. Around $19 \%$ of selected papers reported case study. (Manouselis et al., 2010) conducted a case study to understand the teacher's perceived usefulness and quality of the resources they accessed. Around $16 \%$ of the studies proposed RSs which had been evaluated via a survey. (Hariharan et al., 2019) presented a questionnaire to understand the level of acceptance and support for the recommendation method.

Table 5. Distribution by evaluation method

\begin{tabular}{lll}
\hline Evaluation method & Number of studies & $\%$ \\
\hline Case study & 6 & 18,75 \\
Survey & 5 & 15,63 \\
Experiment & 14 & 43,75 \\
None & 7 & 21,88 \\
\hline
\end{tabular}

As can be seen in Figure 4, the analysis of the results demonstrates a tendency amongst researchers in the experiment evaluation method as a method of approval of their proposals.

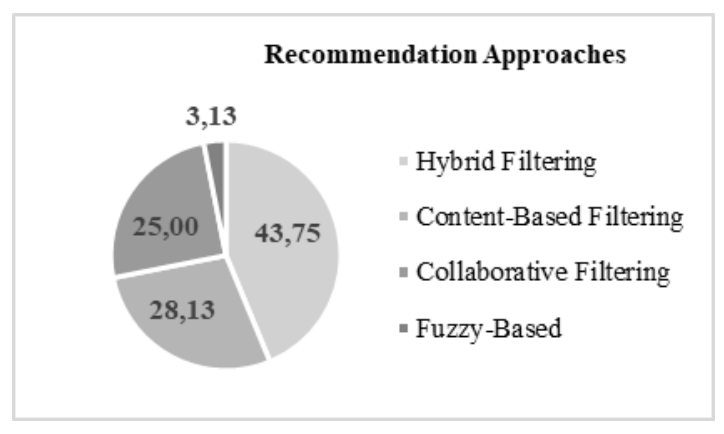

Figure 3. Recommendation approaches

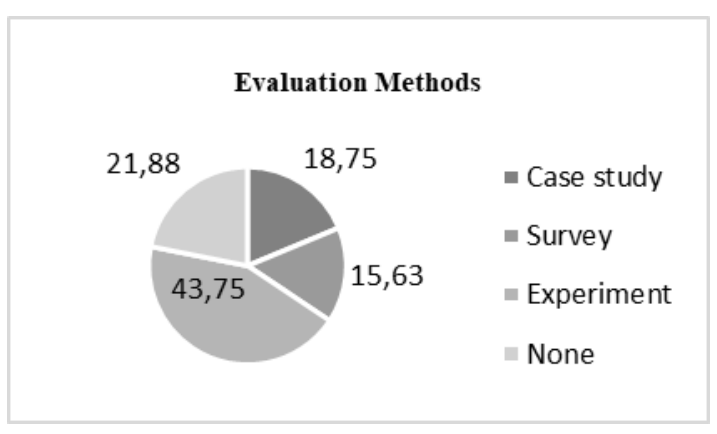

Figure 4. Evaluation methods 


\section{CONCLUSION}

The objective of this review is to conduct a literature review to examine existing recommendation systems for teachers. It represents an important milestone towards proposing an ICT-CFT recommender system for teachers that recommends training material based on teachers' ICT competencies. In this review, 32 primary studies were selected and examined. Then, selected papers were classified according to a set of selected features namely: learning environments, recommendation issues, recommendation approaches and evaluation methods.

This study has revealed that educational portals, repositories, and learning management systems are the widely learning environments used for recommending educational resources to teachers. Results further showed that personalized recommendations for teachers and improving teachers' practices are the main issues addressed by these RS. Moreover, the hybrid approach is the most frequent type of recommender system used in teacher-oriented recommendation systems. In order for the recommendation approaches efficiency to be validated, the method of evaluation by experiment is the mostly used one.

In our future work, we propose to develop a teacher recommender system based on ICT-CFT harnessing OER, that can be embedded in portals and repositories gathering collections of various ICT-CFT aligned resources.

\section{REFERENCES}

Bahritidinov, B. et al. (2011) 'Recommending teachers for collaborative authoring tools', in 11th IEEE International Conference on Advanced Learning Technologies, ICALT 2011, pp. 438-442. doi: 10.1109/ICALT.2011.137.

Brusilovsky, P. et al. (2010) 'Social navigation for educational digital libraries', Procedia Computer Science, 1(2), pp. 2889-2897. doi: 10.1016/S1877-0509(10)00330-3.

Cobos, C. et al. (2013) 'A hybrid system of pedagogical pattern recommendations based on singular value decomposition and variable data attributes', Information Processing and Management, 49(3), pp. 607-625. doi: 10.1016/j.ipm.2012.12.002.

Dhahri, M. and Khribi, M. K. (2021) ‘Teachers' Information and Communication Technology ( ICT ) Assessment Tools : A Review', in IEEE 21th International Conference on Advanced Learning Technologies, ICALT 2021 (accepted).

El-Bishouty, M. M. et al. (2014) 'Smart e-course recommender based on learning styles', Journal of Computers in Education, 1(1), pp. 99-111. doi: 10.1007/s40692-014-0003-0.

Fazeli, S. et al. (2012) 'Exploring social recommenders for teacher networks to address challenges of starting teachers', in 8th International Conference on Networked Learning 2012, pp. 74-80.

Fazeli, S. et al. (2014) 'Towards a Social Trust-Aware Recommender for Teachers', in Manouselis, N. et al. (eds) Recommender Systems for Technology Enhanced Learning: Research Trends and Applications. Springer, New York, NY, pp. 177-194. doi: 10.1007/978-1-4939-0530-0.

Ferreira-Satler, M. et al. (2012) 'Fuzzy ontologies-based user profiles applied to enhance e-learning activities', Soft Computing, 16(7), pp. 1129-1141. doi: 10.1007/s00500-011-0788-y.

Gallego, D. et al. (2013) 'Enhanced recommendations for e-Learning authoring tools based on a proactive context-aware recommender', in Frontiers in Education Conference, FIE, pp. 1393-1395. doi: 10.1109/FIE.2013.6685060.

Garcia-Valdez, M. et al. (2010) 'Fuzzy inference for Learning Object Recommendation', in International Conference on Fuzzy Systems, Barcelona, pp. 1-6. doi: 10.1109/FUZZY.2010.5584322.

García, E. et al. (2009) 'An architecture for making recommendations to courseware authors using association rule mining and collaborative filtering', User Model User-Adap Inter, pp. 99-132. doi: 10.1007/s11257-008-9047-z.

Hariharan, M. et al. (2019) 'Teaching Style Recommender using Machine Learning', 1st IEEE International Conference on Advances in Information Technology, ICAIT 2019, pp. 238-244. doi: 10.1109/ICAIT47043.2019.8987364.

Karga, S. and Satratzemi, M. (2018) 'A hybrid recommender system integrated into LAMS for learning designers', Education and Information Technologies, 23(3), pp. 1297-1329. doi: 10.1007/s10639-017-9668-0.

Karga, S. and Satratzemi, M. (2019) 'Using explanations for recommender systems in learning design settings to enhance teachers' acceptance and perceived experience', Education and Information Technologies, 24(5), pp. $2953-2974$. doi: 10.1007/s10639-019-09909-z.

Khribi, M. K. et al. (2015) 'Recommendation systems for personalized technology-enhanced learning', in Kinshuk and Huang, R. (eds) Ubiquitous Learning Environments and Technologies. Springer-Verlag Berlin Heidelberg, pp. 159-180. doi: https://doi.org/10.1007/978-3-662-44659-1_9. 
Kitchenham, B. and Charters, S. (2007) Guidelines for performing Systematic Literature Reviews in Software Engineering, EBSE Technical Report. doi: 10.1541/ieejias.126.589.

Limongelli, C. et al. (2013) 'A teaching-style based social network for didactic building and sharing', Lecture Notes in Computer Science (including subseries Lecture Notes in Artificial Intelligence and Lecture Notes in Bioinformatics), 7926 LNAI, pp. 774-777. doi: 10.1007/978-3-642-39112-5-110.

Limongelli, C. et al. (2016) 'A recommendation module to help teachers build courses through the Moodle Learning Management System', New Review of Hypermedia and Multimedia, 22(1-2), pp. 58-82. doi: 10.1080/13614568.2015.1077277.

Lu, J. et al. (2015) 'Recommender system application developments: A survey', Decision Support Systems, 74, pp. 12-32. doi: 10.1016/j.dss.2015.03.008.

Manouselis, N. et al. (2010) 'Collaborative recommendation of e-learning resources: An experimental investigation', Journal of Computer Assisted Learning, 26(4), pp. 227-242. doi: 10.1111/j.1365-2729.2010.00362.x.

Miranda, C. et al. (2012) 'A hybrid peer recommender system for an online community of teachers', in CEUR Workshop Proceedings.

Mohamed Ali, B. A. et al. (2017) 'Recommendation of pedagogical resources within a learning ecosystem', in 9th International Conference on Management of Digital EcoSystems, MEDES 2017, pp. 14-21. doi: $10.1145 / 3167020.3167023$.

Mottus, A. et al. (2013) 'Visualization and interactivity in the teacher decision support system', in IEEE 13th International Conference on Advanced Learning Technologies, ICALT 2013, pp. 502-503. doi: 10.1109/ICALT.2013.163.

Pinho, P. C. R. et al. (2019) 'Developments in Educational Recommendation Systems: A systematic review', in 2019 IEEE Frontiers in Education Conference, FIE 2019. pp. 1-7. doi: 10.1109/FIE43999.2019.9028466.

Revilla Muñoz, O. et al. (2016) 'The Skills, Competences, and Attitude toward Information and Communications Technology Recommender System: An online support program for teachers with personalized recommendations', New Review of Hypermedia and Multimedia, 22(1-2), pp. 83-110. doi: 10.1080/13614568.2015.1036132.

Rivera, A. C. et al. (2018) 'Recommendation Systems in Education: A Systematic Mapping Study', in International Conference on Information Technology \& Systems (ICITS 2018), pp. 138-147. doi: 10.1007/978-3-319-73450-7.

Sergis, S. et al. (2014a) 'ICT competence-based learning object recommendations for teachers', 11th International Conference on Cognition and Exploratory Learning in Digital Age, CELDA 2014, (October 2015), pp. 150-157.

Sergis, S. et al. (2014b) 'Towards learning object recommendations based on teachers' ICT competence profiles', in IEEE 14th International Conference on Advanced Learning Technologies, ICALT 2014, pp. 534-538. doi: 10.1109/ICALT.2014.156.

Sergis, S. and Sampson, D. G. (2015) 'Enhancing learning object recommendations for teachers using adaptive neighbor selection', in IEEE 15th International Conference on Advanced Learning Technologies, ICALT 2015, pp. $391-393$. doi: 10.1109/ICALT.2015.50.

Sergis, S. and Sampson, D. G. (2016) 'Learning Object Recommendations for Teachers Based on Elicited ICT Competence Profiles', IEEE Transactions on Learning Technologies, 9(1), pp. 67-80. doi: 10.1109/TLT.2015.2434824.

Soldatova, E. et al. (2014) 'E-Learning Recommender System for Teaching Staff of Engineering Disciplines', International Journal of Engineering Pedagogy (iJEP), 4(3), p. 42. doi: 10.3991/ijep.v4i3.3478.

Tewari, A. S. et al. (2015) 'e-Learning Recommender System for Teachers using Opinion Mining', Lecture Notes in Electrical Engineering, 339, pp. 777-784. doi: 10.1007/978-3-662-46578-3.

Verbert, K. et al. (2012) 'Context-aware recommender systems for learning: A survey and future challenges', IEEE Transactions on Learning Technologies, 5(4), pp. 318-335. doi: 10.1109/TLT.2012.11.

Zapata, A. et al. (2011) 'A Hybrid Recommender Method for Learning Objects', International Journal of Computer Applications.

Zapata, A. et al. (2013) 'A framework for recommendation in learning object repositories: An example of application in civil engineering', Advances in Engineering Software, 56, pp. 1-14. doi: 10.1016/j.advengsoft.2012.10.005.

Zervas, P. et al. (2015) 'Towards Competence-Based Learning Design Driven Remote and Virtual Labs Recommendations for Science Teachers', Technology, Knowledge and Learning, 20(2), pp. 185-199. doi: 10.1007/s10758-015-9256-6. 